\title{
Challenges in laboratory diagnosis of Malaria in a low resource country among cases of acute febrile illness at tertiary care hospital in eastern Nepal: Comparative study on Conventional Vs Molecular approach
}

Pragyan Dahal ( $\triangle$ Pragyandahal55@gmail.com )

Grande International Hospital https://orcid.org/0000-0002-1778-4345

Basudha Khanal

BP Koirala Institute of Health Sciences

Keshav Rai

BP Koirala Institute of Health Sciences

Vivek Kattel

BP Koirala Institute of Health Sciences

Satish Yadav

BP Koirala Institute of Health Sciences

Narayan Raj Bhattarai

BP Koirala Institute of Health Sciences

Research article

Keywords: Malaria, acute febrile illness, Microscopy, Real-time PCR, Rapid diagnostic test

Posted Date: June 19th, 2020

DOI: https://doi.org/10.21203/rs.3.rs-35005/v1

License: (c) (i) This work is licensed under a Creative Commons Attribution 4.0 International License.

Read Full License

Version of Record: A version of this preprint was published at Journal of Tropical Medicine on December 28th, 2021. See the published version at https://doi.org/10.1155/2021/3811318. 


\section{Abstract \\ Background}

For ongoing malaria elimination programme, available methods like microscopy and rapid diagnostic test (RDT) are not able to detect all the cases of malaria in acute febrile illness. These methods are entirely dependent on the course of infection, parasite load and skilled technical resources thus the study was carried out to compare performance of microscopy and RDT which are commonly used in a low resource country along with reference to real-time PCR.

\section{Methods}

Altogether 52 blood samples collected from patients with acute febrile illness were tested by microscopy, RDT and real-time PCR. The results were compared in terms of sensitivity and specificity.

\section{Results}

The test results were as follows: $5.8 \%$ positivity by Microscopy, $13.5 \%$ positivity by RDT and $27 \%$ by real time PCR. Taking into consideration of PCR as a gold standard method microscopy showed $21.4 \%$ sensitivity and $100 \%$ specificity. Likewise, RDT results revealed $28.6 \%$ sensitivity and $92.1 \%$ specificity.

\section{Conclusion}

Despite of various diagnostic tools available, microscopy stills remains the gold standard for the diagnosis and RDT is the user friendly to execute the test under the tree, but our preliminary results emphasized the need to implement the test with the higher sensitivity and specificity in context of malaria elimination programme which could be another important opportunity to understand the parasite circulation in case of low endemic region. However, these results should be further verified with the large study cohort in order to document the submicroscopic infection.

\section{Background}

Malaria is one of the vector borne disease causing the high morbidity and mortality. It is caused by protozoan parasites of the genus Plasmodium which belongs to the phylum Apicomplexa. Five Plasmodium species are reported to cause malaria infecting human namely Plasmodium vivax, Plasmodium falciparum, Plasmodium malariae, Plasmodium ovale and Plasmodium knowlesi [1]. Around 3.2 billion population in 95 different countries falls under risk of importing malaria and greater than 1 billion are at high risk. As reported by the world malaria report in 2016, there were approximately 212 million cases of malaria in the world during 2015 and 429000 deaths due to malaria [2]. 
Plasmodium falciparum and Plasmodium vivax are the most predominant species causing malaria in Nepal. Plasmodium falciparum is recognized as the most virulent due to its ability to attain high levels of parasitaemia during the life cycle as well as responsible for most (91\%) of the morbidity and mortality, due to its complications arising from parasite sequestrations in deep tissues [3]. There are different methods used for the diagnosis of malaria which ranges from simple microscopy to the advance polymerase chain reaction (PCR) based molecular methods. However, each method has advantages and disadvantages. Microscopic blood smear examination has been considered the standard method for diagnosis of malarial parasites but it is dependent upon the parasite load, course of infection and skilled microscopist and alternative methods such as rapid diagnostic test (RDT) have been available [4]. Most of these RDT rely on lateral immunochromatography to detect histidine-rich protein 2 (HRP2), specific to Plasmodium falciparum and lactate dehydrogenase or aldolase, enzymes common to all species. In cases of self-medication that has taken place before medical consultation, results of microscopic examination can be negative while rapid diagnostic test results remain positive [4,5]. However, the false positive reaction has been reported, due to cross-reaction with rheumatoid factors, and lower sensitivity of rapid diagnostic test has been reported especially for Plasmodium ovale, Plasmodium vivax and Plasmodium malariae [6]. Among others, polymerase chain reaction (PCR) methods have been tested for detecting parasites in blood samples along with the identification of species, both in endemic areas and in countries with imported malaria. PCR is a reliable tools for the diagnosis in patients with clinical signs of disease or for epidemiological studies in endemic areas with high sensitivity and specificity [7].

\section{Methods}

\section{Study sites and duration}

This study was conducted at tertiary care hospital (B.P Koirala Institute of Health Science), Dharan, Nepal in department of microbiology during the period of 2017 to 2018 along collaboration with department of internal medicine and pediatrics.

\section{Study design}

A descriptive cross-sectional study was conducted in B.P Koirala Institute of Health Sciences, a tertiary care hospital in Nepal. The inclusion criterion was: patient visiting medicine ward, pediatrics ward, emergency ward and out-patient department with acute febrile illness. An exclusion criterion was: patient visiting pediatrics ward, medicine ward and emergency ward other than acute febrile illness cases.

\section{Study procedure}

\section{Malaria detection from blood films using light microscopy}

Peripheral blood smear (thick and thin blood film) was prepared and staining was done using $10 \%$ Giemsa solution for 10 minutes and microscopic examination of Giemsa stained thick and thin blood smears was performed [8]. 
Quantification of Malaria parasite by Red blood cell (RBC) count method using thin smear

Parasite quantification was done by RBC count method following WHO protocol [9] using the given formula below:

[Please see the supplementary files section to view the equations.]

Percentage of parasitaemia was calculated by counting infected RBC amongst 2000 RBC by using following formula:-

[Please see the supplementary files section to view the equations.]

\section{Malaria detection using rapid diagnostic test (RDT)}

Histidine rich protein-2 and Plasmodium specific lactase dehydrogenase based rapid diagnostic test kit was used for detection of malaria infection by immunochromatography process. The tests were done with rapid diagnostic kit, based on the leaflet provided from its manufacturer instruction.

\section{DNA extraction of blood samples using Qiagen kits}

Blood samples preserved on $0.5 \mathrm{mg}$ EDTA vial were stored at $-20^{\circ} \mathrm{C}$ in order to prevent DNA degradation and blood samples were left to room temperature for 30 minutes before the extraction process was carried out. DNA was extracted from $200 \mu \mathrm{l}$ of blood samples using QIAamp DNA blood mini kit (Qiagen, Hilden, Germany, Catalog number 51104) as instructed on manufacturer instruction on QIAamp. DNA mini Handbook [10].

\section{Taqman assay based real-time PCR}

Purified DNA samples were amplified using a Qiagen Rotor Gene Q system using abTes ${ }^{\mathrm{Tm}}$ Malaria 5 qPCRKit (Catalog number 300229) by a set of specific primers for each Plasmodium species designed by a manufacturer company. At first, master mix solution was prepared using the following scheme: primer/probe: $2 \mu \mathrm{l}$, enzyme/reaction mix: $6 \mu \mathrm{l}$, nuclease-free water: $12 \mu \mathrm{l}$ and template: $5 \mu \mathrm{l}$. The thermal cycler was programmed as phase 1 at $95^{\circ} \mathrm{C}$ for $2 \mathrm{~min}$ to implement one cycle, phase 2 at $60^{0} \mathrm{C}$ for 20 second to produce 30 cycle and phase 3 at $68^{\circ} \mathrm{C}$ for 1 minute per kb to generate 30 cycle on the basis of company manufacturer instruction. Fluorescence intensity was measured by the Rotor gene $\mathrm{Q}$ software and the graph between Fluorescence intensity vs. number of cycle was plotted [11].

\section{Amplification of Plasmodium species identified by real-time PCR}

Real time PCR based taqman assay was performed in order to identify species and compare the results with microscopy and RDT. Minicircular DNA of Plasmodium species was amplified. Five fluorescent dye i.e. FAM, HEX, ROX, Cy5, and Quasar 705 were used to detect different five species of Plasmodium [11] which were described below: 
FAM (Green) - Plasmodium falciparum

HEX (Yellow) - Plasmodium malariae
Cy5 (Red) - Plasmodium ovale

ROX (Orange) - Plasmodium vivax

Quasar 705(Crimson) - Plasmodium knowlesi

\section{Data management and statistical analysis}

The collected data were entered in the excel sheet, coding was done for different variables and the data was transferred to SPSS version 11.5 [12]. The data was then summarized using the frequencies and relative frequencies (percentages). The comparison between different diagnostic tools were done using chi-square test using real-time PCR as a gold standard tool in order to calculate sensitivity, specificity, positive predictive value, negative predictive value and accuracy of diagnostic tool.

\section{Results}

\section{Age wise and sex wise distribution of cases}

In our study, 52 individuals were involved and equal number $(\mathrm{n}=26)$ of male and female were participated. The highest number of participants were from age group of 10-19 $(n=12)$. Lowest participants were in old age group 70-79. Results were shown in fig 1.

\section{Microscopic examination on peripheral blood smears:}

Out of total 52 whole blood sample, $n=3(6 \%)$ samples were positive by microscopic examination and $n=49(94 \%)$ samples were negative by microscopic findings.

Plasmodium species identification and quantification was done from the positive findings in Giemsa stained smear using light microscopy following RBC count method from the thin blood film to estimate the level of parasitemia and their percentages were shown in table 1 below.

Table 1: Quantification of parasitemia by RBC count method among plasmodium species identified by blood film using light microscope 


\begin{tabular}{|l|l|l|l|l|l|}
\hline $\begin{array}{l}\text { Sample } \\
\text { code }\end{array}$ & $\begin{array}{l}\text { Parasites species } \\
\text { identification by } \\
\text { blood films }\end{array}$ & $\begin{array}{l}\text { Infected RBC } \\
\text { per 20 field } \\
(100 x)\end{array}$ & $\begin{array}{l}\text { Parasites/ } \\
\boldsymbol{~} \mathbf{l}\end{array}$ & $\begin{array}{l}\text { Infected } \\
\text { RBC per } \\
\text { 2000 RBC }\end{array}$ & $\begin{array}{l}\text { Parasitemia } \\
\text { (\%) }\end{array}$ \\
\hline MP125 & $\begin{array}{l}\text { Trophozoites of } \\
\text { Plasmodium } \\
\text { falciparum }\end{array}$ & 12 & $12000 / \mu l$ & 5 & $0.25 \%$ \\
\hline MP134 & $\begin{array}{l}\text { Trophozoites of } \\
\text { Plasmodium } \\
\text { falciparum }\end{array}$ & 10 & $10000 / \mu l$ & 4 & $0.2 \%$ \\
\hline MP146 & $\begin{array}{l}\text { Scizoints of } \\
\text { Plasmodium vivax }\end{array}$ & 7 & $7000 / \mu l$ & 3 & $0.15 \%$ \\
\hline
\end{tabular}

Rapid diagnostic tests (RDT) on whole blood sample:

Out of total 52 blood samples, $n=7(13 \%)$ blood samples were found to be positive cases and $\mathrm{n}=45(87 \%)$ cases were found to be negative by immunochromatography test.

Taqman assay based Real-time PCR results:

Out of total 52 whole blood samples, $n=14(27 \%)$ blood samples were found to be positive for Plasmodium falciparum and Plasmodium vivax and $n=38(73 \%)$ were found to be negative by Real-time PCR assay. The graphical representation of Real-time PCR amplification of 52 blood samples of patients with acute febrile illness was analyzed and interpreted. The blood samples were considered as positive due to the fluorescent intensity which were greater than the threshold value or cut off value which were shown in fig 2 and fig 3.

Table 2: Sensitivity and Specificity of light microscopy and rapid diagnostic test (RDT) comparing with the gold standard test (Real-time PCR)

\begin{tabular}{|l|l|l|l|l|}
\hline \multirow{3}{*}{$\begin{array}{l}\text { Microscopic } \\
\text { examination }\end{array}$} & \multicolumn{4}{|l|}{ Gold Standard Test (Real-time PCR) } \\
\cline { 2 - 5 } & & Positive & Negative & Total \\
\cline { 2 - 5 } & Positive & $3(\mathrm{TP})$ & $0(\mathrm{FP})$ & 3 \\
\cline { 2 - 5 } & Negative & $11(\mathrm{FN})$ & $38(\mathrm{TN})$ & 49 \\
\cline { 2 - 5 } & & Total=14 & Total=38 & Total=52 \\
\hline
\end{tabular}




\begin{tabular}{|l|l|l|l|l|}
\hline \multirow{2}{*}{ Rapid Diagnostic Test (RDT) } & \multicolumn{4}{|l|}{ Gold Standard Test (Real-time PCR) } \\
\cline { 2 - 5 } & & Positive & Negative & Total \\
\cline { 2 - 5 } & Positive & $4(\mathrm{TP})$ & $3(\mathrm{FP})$ & 7 \\
\cline { 2 - 5 } & Negative & $10(\mathrm{FN})$ & $35(\mathrm{TN})$ & 45 \\
\cline { 2 - 5 } & & Total=14 & Total=38 & Total=52 \\
\hline
\end{tabular}

(TP: True Positive, FP: False Positive, FN: False Negative, TN: True Negative)

The performance characteristics of Light Microscopy, Rapid Diagnostic test and Real time PCR was calculated by using Chi square test analyzed by SPSS version 19 in order to estimate the Sensitivity, Specificity, Positive predictive value (PPV), Negative predictive value (NPV) and overall calculated accuracy of diagnostic tools are shown below in table 3.

Table 3: Performance characteristics of Microscopy, Rapid diagnostic test and Real-time PCR

\begin{tabular}{|c|l|l|l|l|l|}
\hline Diagnostic Equipment & Sensitivity & Specificity & PPV & NPV & Accuracy \\
\hline Microscopic examination & $21.4 \%$ & $100 \%$ & $100 \%$ & $77.6 \%$ & $78.84 \%$ \\
\hline Rapid Diagnostic Test & $28.6 \%$ & $92.1 \%$ & $57.14 \%$ & $77.8 \%$ & $75 \%$ \\
\hline $\begin{array}{c}\text { Real-time PCR } \\
\text { (Gold standard test) }\end{array}$ & $100 \%$ & $100 \%$ & $100 \%$ & $100 \%$ & $100 \%$ \\
\hline
\end{tabular}

\section{Discussion}

Accurate estimation of malaria burden exhibits vital role planning on effective malaria control strategies and developing a correct treatment regimen. The diagnosis of malaria has been a remarkable challenge, 
especially in poor region, due to availability of limited resource, equipment and methods. Laboratory diagnostic methods have been mandatory for detection of cases and timely initiation of appropriate therapy which are essential for malaria management.

Our study had aimed to compare the performance of three diagnostic tools i.e. microscopy, RDT and realtime PCR. Microscopy and rapid diagnostic test are routinely used diagnostic tools to determine the sensitivity, specificity, positive predictive value, negative predictive value and accuracy of the tools. Other country research shows five-fold difference on prevalence when compared to prevalence estimated between light microscopy and PCR $[13,14]$. In many parts of Nepal and other malaria endemic developing countries, light microscopy is still widely used as the standard tool due to limited supply of RDTs as well as greater possibilities of RDT kits owing out of stock [15-17]

Our results highlighted low sensitivity of light microscopy and we had observed a greater than four-fold difference between parasite prevalence estimated by light microscopy in compared to real-time PCR. Other several studies conducted in some countries of south East Asia with respect to systemic review [13] had similar report with our study. On the basis of study conducted in Myanmar showed the rate of detection of malaria was higher with $100 \%$ sensitivity and specificity of real-time PCR over the performance of light microscopy and RDT [18]. Several limitations of light microscopy had been documented in past study such as its limit of detection (LOD) of about 50 parasites/ $\mu \mathrm{l}$ of blood [19]. The LOD varies from 30-100 parasites/ $\mu$ l between expert and field microscopists. This implies that most infections were not detected by light microscopy and RDT. Various demerits of RDT includes limited potential to identify species and unable to quantify parasitaemia. Observation of false positivity in RDT occurs due to cross-reaction and limit of detection that ranges from $50-100$ parasites $/ \mu l[6,20,21]$. We observed $5.76 \%$ of false positive cases when we had compared with gold standard test (qPCR). On the basis of experiment conducted by Bell D, Wilson $S$ et al on comparison of different RDT, 8.33\% was found to be false positive [20]. Similar study done in Equatorial Guinea had represented $13.3 \%$ of false positive cases by RDT [21]. This resulted from cross reaction of rheumatoid factor or residue of HRP-2 antigen circulating in blood of patient even after parasite clearance [6,22]. Rapid diagnostic test kits applied in our study was able to distinguish only single species i.e Plasmodium falciparum . This was due lack of separately divided pLDH panel for different Plasmodium species. RDT sensitivity was found to be $28.6 \%$ in our study and specificity of $92 \%$. Study conducted by Moody et al and Bell D, Wilson S et al determined RDT sensitivity had ranged from $60-80 \%$ and specificity $80-90 \%$ based on detection of different Plasmodium species $[5,20]$. Similar study in Tanzania had also determined $0.92 \%$ of false positive cases by RDT in their survey [23].

In our study light microscopy and RDT had determined false negativity of $94 \%$ and $92 \%$ respectively among the cases of acute febrile illness. Hence, it was concluded low sensitivity of microscopy and RDT compared to real-time PCR where $21 \%$ and $19 \%$ of microscopy and RDT negative sample was found to be positive with real-time PCR. Thus we suspect submicroscopic infection in our region which is successfully detected by real-time PCR. Identical results were observed on experiment conducted Berzosa P, Lucio AD, Romay-Burza M et al where $19.4 \%$ were false negative by microscopy and $13.3 \%$ false 
negative by RDT [21]. False negativity by microscopy and RDT mostly occurred in the past study due to submicroscopic infection [6]. This findings had been explained by study of Okel LC, Ghani AC et al and Wampfler R, Mwingira $\mathrm{F}$ et al that both microscopy and RDT was unsucessful to detect the submicroscopic infection due to its low limit of detection that ranges from 50-100 parasites/ $\mu \mathrm{l}[13,24]$.

Our microscopy positive results had significantly high level of parasitaemia ranging 7000-12000 parasites $/ \mu$ l which resembles $0.15-0.25 \%$ quantified by RBC count method. Similar study was conducted by Koepfli C, Nguitragool W, Hofmann NE et al had revealed light microscopy were able to quantify only upto $0.25-0.0625 \mu \mathrm{l}$ of parasitaemia based on skilled microscopist whereas real-time PCR had quantified less than $0.03 \mu$ l of parasites [25].

Microscopic examination in our study had low sensitivity (21.4\%) and high specificity (100\%) with accuracy of $78.84 \%$.Study conducted by Mogeni P, William TN, Omedo I et al had determined despite of lower sensitivity compared with molecular tools, specificity of light microscopy was found to be $100 \%$ that had retained its diagnostic superiority in many endemic fields [26]. There are very few reported cases of false diagnosis of light microscopy. Study of Han TZ, Aye KH et al revealed claiming false diagnosis of light microscopy on determining Plasmodium vivax where they had reported as Plasmodium falciparum which was confirmed later by PCR [27].

Our research had determined real-time PCR as a standard tool in malaria detection despite of its expensive reagent and requirement of expertise. Real-time PCR performance showed better sensitivity and specificity than the conventional PCR which are represented in several past research study $[24,28$, 29]. Earlier study was done by Gatti S, Gramegna $M$ et al had reported that conventional PCR had failed to detect mixed infection which were detected by microscopy [30]. The real-time PCR performance for the investigation of malaria parasite from blood samples amongst cases of acute febrile illness showed superior performance in comparision with microscopy and RDT. Similar study on PCR conducted by Kamau E, Tolbert LS et al reflected real-time PCR as a most confirmatory tool for the diagnosis of malaria for clearing doubts in between unoverlapped results of light microscope and RDT [28]. According to Vincent 00 , Eekei $E$ et al sensitivity and specificity of PCR was found to be $100 \%$ where as $58 \%$ were diagnosed false positive by microscopy and $60 \%$ were diagnosed false positive by RDT [31]. False diagnosis by light microscopy might result due to several factors based on experience as well as reagent quality [32].Several studies had shown the limit of detection of real-time PCR ranging from 0.021 parasite/ $\mu$ l of blood [33], superior to limit of detection of microscopy 50 parasites/ $\mu$ and rapid diagnostic test $50-100$ parasites/ $\mu \mathrm{l}[5,32,34]$. Hence due to high sensitivity $(100 \%)$, specificity $(100 \%)$ and accuracy (100\%) in our research, several support of literature from a researcher including detection of submicroscopic infection as well as of its potential of quantifying parasite load [30,34] employed realtime PCR a superior diagnostic as well as a confirmatory tools in erogenous thickness of smear microscopy and enhanced detection of scanty parasitemia as well as its accuracy on reporting cases of malaria with a history of patient subjected to self-medication [33]. Therefore we had considered real-time PCR as a gold standard tool in our research. 
Our PCR data had helped to understand the difference between light microscopy and RDT results in this study. The LOD of RDT was roughly comparable to light microscopy in the field survey, although the newer generation of RDTs had showed a higher sensitivity than past ones [5, 6]. Moreover, RDT had performed better than light microscopy in surveys which was shown in various study $[23,24]$. The use of qPCR in our study increased the prevalence of malaria approximately two fold incomparision to RDT and greater than four-fold comparing that with the microscopy, which was similar to differences between PCR and RDT detected prevalence reported elsewhere [6,35].

Light microscopy efficiency seems inadequate for surveillance of parasite infections in Nepal at a certain area when intensity of transmission rate is shifting from high to low. This test had the advantage of allowing empirical treatment for symptomatic individuals with positive RDT results. Our preliminary results emphasized the need to implement the test with the higher sensitivity and specificity in context of malaria elimination programme which provides opportunity to understand the parasite circulation in case of low endemic region. However, these results should be further verified with the large study cohort in order to document the submicroscopic infection.

\section{Conclusion}

Lowest performance was shown by light microscopy for detecting both Plasmodium falciparum and Plasmodium vivax parasites. This implies the presence of a large proportion of submicroscopic parasitemia at tertiary care hospital that had been vastly underestimated. Performance of RDT was sensitive than light microscopy, as it detected four Plasmodium carriers identified by real-time PCR. However, our molecular tool adds to our understanding of the malaria transmission level, in the sense that it can determine recently cleared infections whether treated or not which are no more detectable by RDT i.e due to HRP-2 residue remaining even after the parasite clearance and microscopy due to low parasite load after treatment. Thus, using tools such as real-time PCR, RDT and light microscope which together were able to detect actual parasitemia and recent infections and may provide the most precise information to decide on the best malaria control strategies.

\section{Abbreviations}

\section{RDT}

Rapid diagnostic test

PCR

Polymerase chain reaction

qPCR

Quantitative PCR

HRP

Histidine rich protein

PPV

Positive predictive value 
NPV

Negative predictive value

\section{Declarations}

Ethics approval and consent to participate

Ethical clearance was obtained from Institutional Review Board, BPKIHS. (Ref. No: 257/074/075-IRC (Code No: IRC/1060/017)

Consent to participate: Not Applicable

Consent for publication: Not Applicable

Data Availability

Data are available upon request from the author.

Competing interests

The authors declare that there is no conflict of interest.

\section{Funding}

There is no extra source of funding, the research was conducted in department of microbiology.

\section{Author contribution}

Conceptualization: PD, NRB, BK. Investigation: PD. Methodology: PD, NRB, BK, KR. Resources: PD, NRB, BK, SY, KR, VK. Supervision: NRB, BK, VK, SY. Data management and interpretation of Molecular assay: NRB, KR. Writing-original draft: PD. Writing-review and editing: PD, NRB .All authors read and approved the final manuscript

\section{Acknowledgement}

I would like to acknowledge highly indebted to all faculty members of department of Microbiology and Dr.Surendra Urawn for support on statistical analysis.

\section{References}

1. Cox-Singh J, Davis TM, Lee KS, Shamsul SS, Matusop A, Ratnam S, Rahman HA, Conway DJ, Singh B. Plasmodium knowlesi malaria in humans is widely distributed and potentially life threatening. Clinical Infectious Disease. 2008;46:165-71.

2. WHO. World Malaria Report 2016.http://www.who.int/malaria/publications/world-malaria-report2016/report/en/.Accessed on 10 January 2017. 
3. Antinori S, Galimberti L, Milazzo L, Corbellino M. Plasmodium knowlesi: the emerging zoonotic malaria parasite. Acta Trop. 2013;125:191-201.

4. De Pina JJ, Garnotel E, Hance P, Vedy S, Rogier C. MorillonDiagnosis of imported malaria in FranceJ. Med Mal Infect. 2007;37:710-5. doi:10.1016/j.medmal.2007.09.001.

5. Moody A. Rapid diagnostic tests for malaria parasites. ClinMicrobiol Rev. 2002;15:66-78. doi:10.1128/CMR.15.1.66-78.2002.

6. De Monbrison F, Gerome P, Chaulet JF, Wallon M, Picot S, Peyron F. Comparative diagnostic performance of two commercial rapid tests for malaria in a non-endemic area.Euro $\mathrm{J}$ clinmicrobiol\& infect dis.2004; 23:784-786.

7. Berry A, Benoit-Vical F, Fabre R, Cassaing S, Magnaval JF. PCR-based methods to the diagnosis of imported malaria. Parasite. 2008;15:484-8.

8. Centers for Disease control and Prevention (CDC). - Malaria-diagnostic procedure [Internet]. Available from https://www.cdc.gov/dpdx/diagnosticprocedures/blood/specimenproc.html. Accessed on 15 March 2017.

9. WHO. Malaria microscopy Standard Operating Procedure (MM-SOP-09) 2016 [Internet] available at . Accessed on June 15, 2017.

10. QIAamp DNA Mini and blood mini Handbook. 2016. User instruction. Retrived from www.qiagen.com. Accessed on 15 September 2018.

11. AlT biotech 2016. A real time PCR (qPCR) Assay for the speciation of P.falciparum, P.vivax, P.malariae, P.ovale and P.knowlesii: User instruction. Retrived from http://aitbiotech.com. Accessed on 15 September 2018.

12. SPSS Inc. SPSS 11.5 for Windows. Chicago: SPSS; 2002.

13. Okell LC, Ghani AC, Lyons E, Drakeley CJ. Submicroscopic infection in Plasmodium falciparumendemic populations: a systematic review and meta-analysis. J Infect Dis. 2009;200:1509-17. 10.1086/644781.

14. Rantala AM, Taylor SM, Trottman PA, Luntamo M, Mbewe B, Maleta K, Meshnick SR. Comparison of real-time PCR and microscopy for malaria parasite detection inMalawian pregnant women. Mal J. 2010;9:269.

15. DoHS. Annual Report 2010/2011. Kathmandu: Department of Health Services, Ministry of Health and Population, Government of Nepal; 2012.

16. EDCD

EDCD. Nepal Malaria Strategic Plan 2011-2016 (Revised Version- December 2011) Kathmandu: Epidemiology and Disease Control Division, Department of Health Services, Ministry of Health and Population, Government of Nepal; 2011.

17. EDCD. The Internal Assessment of Malaria and Kala-azar Control Activities. 2004, 2005 and 2006.Kathmandu: Epidemiology and Disease Control Division, Department of Health Services, Ministry of Health and Population, Government of Nepal; 2007. 
18. Wang B, Han S-S, Cho C, Han J-H, Cheng Y, Lee S-K, et al. Comparison of microscopy, nested-PCR, and real-time-PCR assays using high-throughout screening of pooled samples for diagnosis of malaria in asymptomatic carriers from areas of endemicity in Myanmar. J Clin Microbiol. 2014;52:1838-45.

19. Wongsrichanalai C, Barcus MJ, Muth S, Sutamihardja A, Wernsdorfer. A review of Malaria of Malaria tools: Microscopy and Rapid Diagnostic Test (RDT). Am J Trop Med Hyg. 2007 (Suppl 6):119-127.

20. Bell D, Wilson S, Martin L. False-positive results of a plasmodium falciparum histidine rich protein 2 detecting malaria rapid diagnostic test due to high sensitivity in a community with fluctuating low parasite density. Am J Trop Med Hyg. 2005;73(1):199-203.

21. Berzosa P, Lucio A, Romay-Barja M, et al. Comparison of three diagnostic methods (microscopy, RDT, and PCR) for the detection of malaria parasites in representative samples from Equatorial Guinea. Malar J. 2018;17(1):333.

22. Starzengruber P, Fuehrer HP, Ley B, Thriemer K, Swoboda P, Habler V, Jung M, Graninger W, Wasif A, Khan W, Haque R, Noedl H. High prevalence of asymptomatic malaria in south-eastern Bangladesh. Mal J. 2014;13:16-8.

23. Mahende C, Ngasala B, Lusingu J, Yong T, Lushino P, et al. Performance of rapid diagnostic test, blood-film microscopy and PCR for the diagnosis of malaria infection among febrile children from Korogwe District. Tanzania Mal J. 2016;15:1-7.

24. Wampfler R, Mwingira F, Javati S, Robinson L, et al. Strategies for detection of Plasmodium species gametocytes. PLoS ONE Journal. 2013;8(9):76-88.

25. Koepfli C, Nguitragool W, Hofmann NE, et al. Sensitive and accurate quantification of human malaria parasites using droplet digital PCR (ddPCR). Sci Rep. 2016;6:39-41.

26. Mogeni P, Williams TN, Omedo I, Kimani D, Ngoi JM, Mwacharo J, et al. Detecting Malaria Hotspots: A Comparison of Rapid Diagnostic Test, Microscopy, and Polymerase Chain Reaction. J Infect Dis. 2017;216:1091-8.

27. Han TZ, Han KT, Aye KH, Hlaing T, Thant KZ, Vythilingam I. Comparison of microscopy and PCR for the detection of human Plasmodium species and Plasmodium knowlesi in southern Myanmar. Asian Paci J Trop Biomed. 2017;7:680-5.

28. Kamau E, Tolbert LS, Kortepeter L, Pratt M, Nyakoe N, Muringo L, Ockenhouse CF. Development of a highly sensitive genus-specific quantitative reverse transcriptase real-time PCR assay for detection and quantitation of plasmodium by amplifying RNA and DNA of the $18 \mathrm{~S}$ rRNAgenes. J Clin Microbio. 2011;49(8):2946-53.

29. Murungi M, Fulton T, Reyes R, Matte M, Ntaro M, Mulogo E, et al. Improving the specificity of Plasmodium falciparum malaria diagnosis in high-transmission settings with a two-step rapid diagnostic test and microscopy algorithm. J ClinMicrobiol. 2017;55:1540-9.

30. Gatti S, Gramegna M, Bisoffi Z, Raglio A, Gulletta M, Klersy C, et al. A comparison of three diagnostic techniques for malaria: a rapid diagnostic test (NOW®Malaria), PCR and microscopy. Annals of Trop Med \&Parasitol. 2007;101:195-204. 
31. Vincent OO, Eekei E, Obisakin F. Comparison of nested PCR and conventional analysis of Plasmodium parasites in Kano, Nigeria. European J Clin\& Biomed Sci. 2017;3:85.

32. Craig MH, Sharp BL, et al. Comparative evaluation of four techniques for the diagnosis of Plasmodium falciparum infections. J Trop Med. 1997;3:279-82.

33. Coleman RE, Sattabongkot J, Promstaporm S, et al. Comparison of PCR and microscopy for the detection of asymptomatic malaria in a Plasmodium falciparum/vivax endemic area in Thailand. Malar J. 2006;5:121.

34. Mueller I, Betuela I, Ginny M, Reeder JC, Genton B. The sensitivity of the optimal rapid diagnostic test to the presence of Plasmodium falciparum gametocytes compromises its ability to monitor treatment outcomes in an area of Papua New Guinea in which malaria is endemic. J clinmicrobiol. 2007;45:627-30.

35. Mosha JF, Sturrock HJ, Greenhouse B, Greenwood B, Sutherland CJ, Gadalla N, Drakeley C, Kibiki G, Bousema T, Chandramohan D, Gosling R. Epidemiology of sub patent Plasmodium falciparum infection: implications for detection of hotspots with imperfect diagnostics. Mal J, 2013; 12; 21-228.

\section{Figures}

\section{Fig 1}

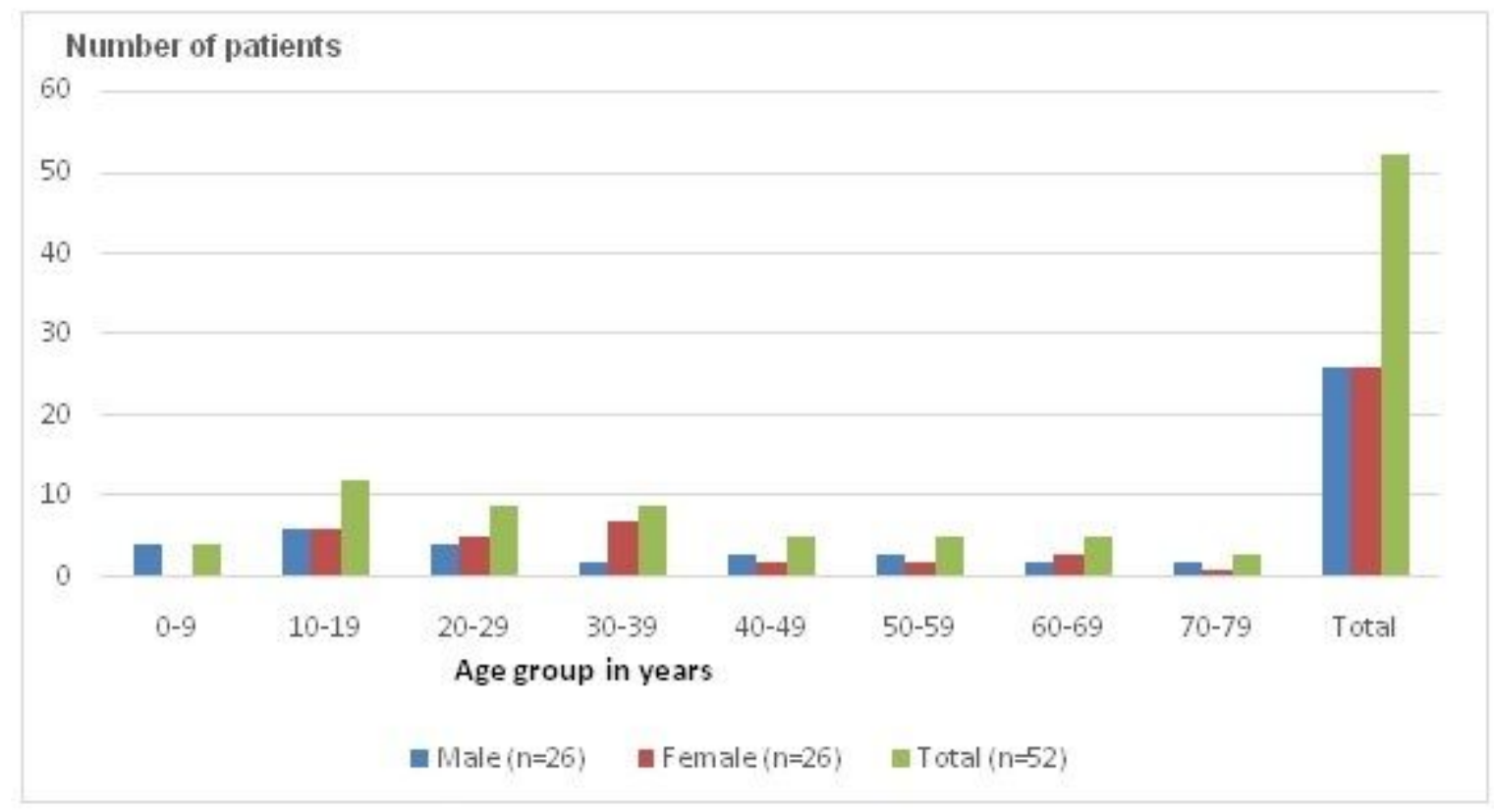

\section{Figure 1}

Age and sex wise distribution of cases of patient with acute febrile illness 
Fig 2

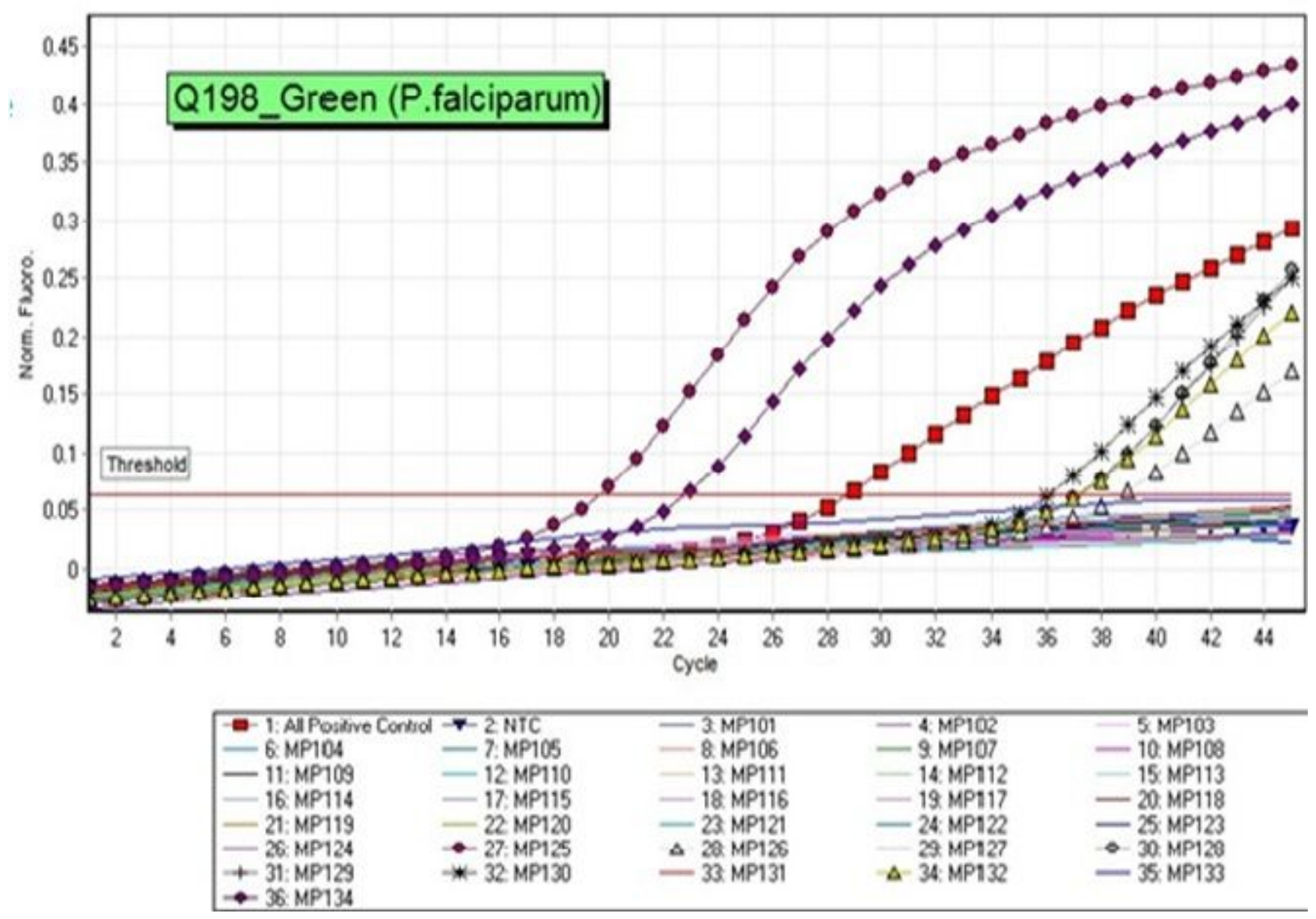

Figure 2

Graphical representation of Real-time PCR amplification of blood samples of patients infected by Plasmodium falciparum. 
Fig 3

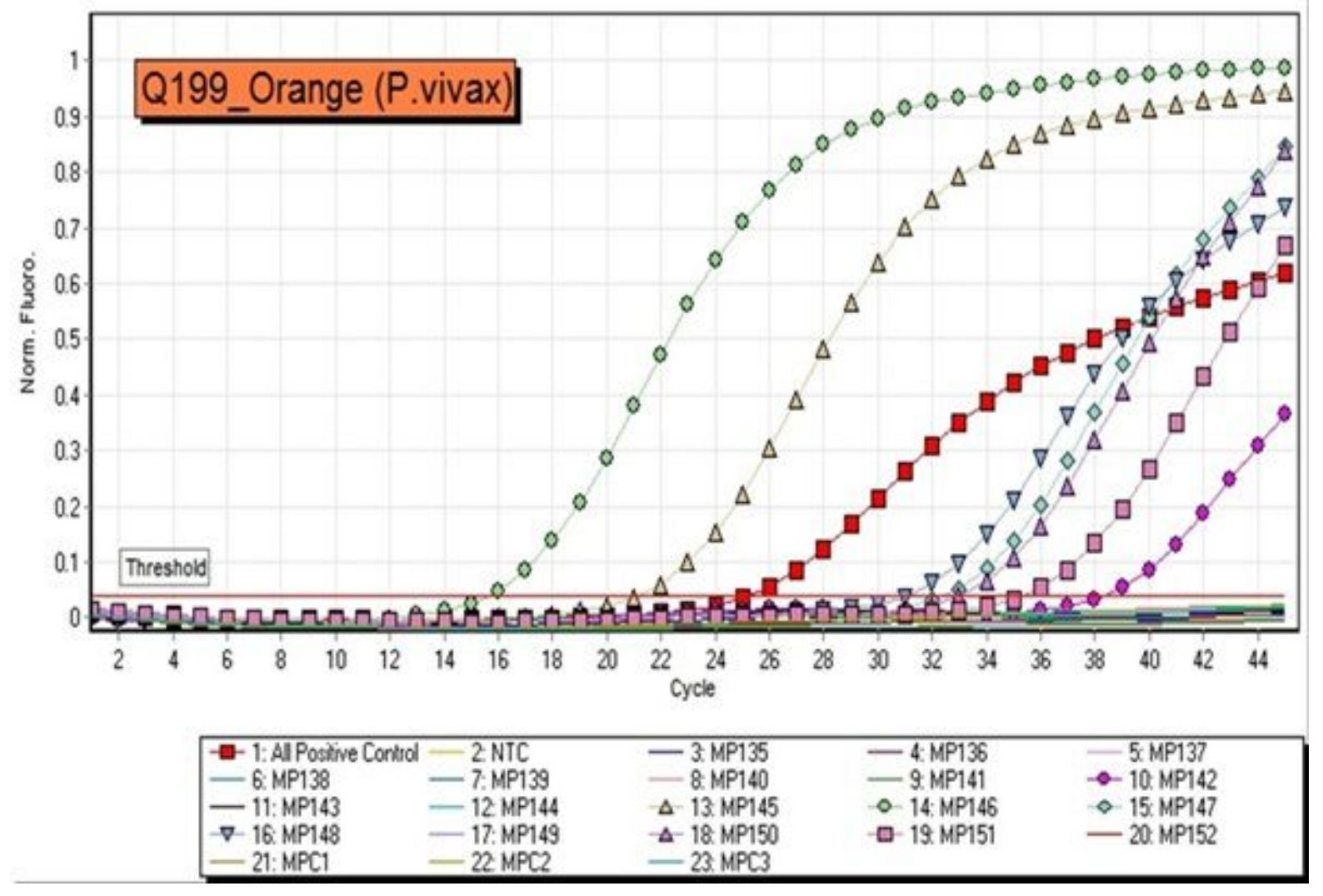

Figure 3

Graphical representation of Real-time PCR amplification of blood samples of patients infected by Plasmodium vivax.

\section{Supplementary Files}

This is a list of supplementary files associated with this preprint. Click to download.

- Equations.docx

- Illustration.pdf 